Form Approved

OMB No. 1902-0121

\title{
PATENT CERTIFICATION
}

The Regents of the University of Colorado

DE-FG0204ER 15589

DOE Prime and/or Subcontract Nos.

Contractor hereby certifies that:

1. All procedures for identifying and disclosing subject inventions as required by the patent clause of the contract have been followed throughout the reporting period.

YES

2. There were no subcontracts or purchase orders involving research, development, and demonstration except as follows:

\section{NONE}

3. No inventions or discoveries were made or conceived in the course of or under this contract other than the following (Certification includes $\boldsymbol{\Downarrow}$, does not include $\square$ all subcontracts): NONE

TITLE INVENTOR DATEREPORTED

4. The completion date of this contract is as follows: October 31,2005

5. The following period is covered by this certification:

\begin{tabular}{lcc} 
Inception & August 1, & 2004 \\
\hline Month & Day & Year
\end{tabular}

The Regents of the University of Colorado Contractor

Campus Box 572

Boulder, CO 80309-0572

Address

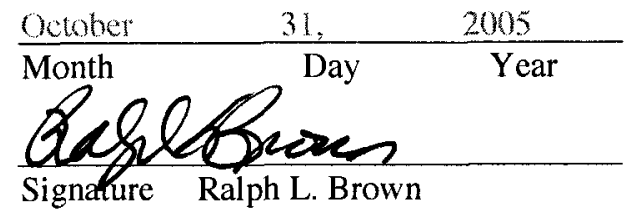

Associate Director, Office of Contracts and Grants

\section{Title}

$5 / 10 / 06$

Date of Certification

Submit one copy to:

Robert J. Fisher, Deputy Chief Counsel

Intellectual Property Counsel

Chicago Operations Office

U.S. Department of Energy

* Also include Subcontract No.

if available

9800 South Cass Avenue

Argonne, IL 60439 
Scientific Final Report for DOE-FG02-04ER15589 Project Number: 1541044

PI Hartmut Spetzler

\title{
Seismic Absorption and Modulus Measurements in Porous Rocks in Lab and Field: Physical, Chemical, and Biological Effects of Fluids (Detecting a Biosurfactant Additive in a Field Experiment)
}

\begin{abstract}
We have been exploring a new technology that is based on using low-frequency seismic attenuation data to monitor changes in fluid saturation conditions in two-fluid phase porous materials. The seismic attenuation mechanism is related to the loss of energy due to the hysteresis of resistance to meniscus movement (changes in surface tension, wettability) when a pore containing two fluids is stressed at very low frequencies $(<10 \mathrm{~Hz})$. This technology has potential applications to monitoring changes in (1) leakage at buried waste sites, (2) contaminant remediation, and (3) flooding during enhanced petroleum recovery We have concluded a three year field study at the Maricopa Agricultural Center site of the University of Arizona. Three sets of instruments were installed along an East-West line perpendicular to the $50 \mathrm{~m}$ by $50 \mathrm{~m}$ irrigation site. Each set of instruments consisted of one three component seismometer and one tiltmeter. Microseisms and solid Earth-tides served as strain sources. The former have a power peak at a period of about 6 seconds and the tides have about two cycles per day. Installation of instruments commenced in late summer of 2002. The instruments operated nearly continuously until April 2005. During the fall of 2003 the site was irrigated with water and one year later with water containing $150 \mathrm{ppm}$ of a biosurfactant additive. This biodegradable additive served to mimic a class of contaminants that change the surface tension of the irrigation fluid. Tilt data clearly show tidal tilts superimposed on local tilts due to agricultural irrigation and field work. When the observed signals were correlated with site specific theoretical tilt signals we saw no anomalies for the water irrigation in 2003 , but large anomalies on two stations for the surfactant irrigation in 2004. Occasional failures of seismometers as well as data acquisition systems contributed to less than continuous coverage. These data are noisier than the tilt data, but do also show possible anomalies for the irrigation with the surfactant. The quantity of data is large and deserves careful analysis. Detailed analyses of the two data sets are ongoing.
\end{abstract}

\section{Introduction}

In this report we present the results of a field study in which we explored the detection of the infiltration of contaminants through the vadose zone into the ground water. The field investigation was based on laboratory experiments where the influence of contaminants on fluid flow across solid surface was studied. Contaminants, which alter the surface tension, affect the meniscus properties and thus the flow of fluids in a partially saturated medium. 


\section{Background}

Attenuation measurements are inherently difficult and any experimental flaw in the design of the instrument or in executing the measurement can easily lead to erroneous results. We therefore designed and built an Attenuation Spectrometer (see fig. 1) and a Qstandard for calibration and verification purposes (W. Brunner et al, 2003, see fig. 2). The standard was built from materials with known properties. The geometry of the standard was chosen such that an attenuation peak occurs in the frequency range of interest. The agreement between design values of absolute attenuation and the measured values was very good, both in terms of frequency and absolute attenuation.

Early measurements on rocks (T. Chelidze et al, 1996 see fig. 3) showed unexpected results that could not easily be explained by conventional wisdom, i.e. by considering viscosity, aspect ratios and simple flow from pore to pore. Since rocks are very complicated in terms of their chemistry as well as their internal geometry, we retracted from rock measurements to simpler systems. We studied flow through simple capillary tubes (W. Brunner and H. Spetzler 2001, see fig. 4) and between parallel plates (H. Schuett and H. Spetzler 2001, and W. Wait et al 1997). We observed and measured time dependent wetting of surfaces and the associated forces and contact angles for menisci. When the surfaces were exposed to various contaminants, that is, to chemicals that changed the surface tension, we noted large changes in the hystereses in the forces required for wetting and un-wetting.

Flow behavior parameters in quasi static experiments were confirmed in single crack experiments. We were able to quantitatively understand the frequency dependent attenuation in the single crack experiments in terms of measured parameters from the flow experiments.

With this newfound confidence in understanding attenuation in single cracks we returned to measurements in rocks. While we can not hope to quantitatively predict the attenuation from measured rock and fluid properties, we were convinced that the phenomena we had found in the quasi static and the dynamic single crack experiments were also controlling the attenuation in a "clean" and "contaminated" rock (W. Brunner and H. Spetzler 2002, see fig. 5).

Based on the above laboratory results we embarked on a field experiment.

\section{The field experiment}

To scale laboratory experiments to the field provides many challenges. Our experiments required low frequency actuators and detectors. For detectors we employed seismometers and tilt meters that are commercially available. Commercially available actuators such as explosions and vibration devices generate little low frequency energy, are very costly and potentially destructive. We chose the natural sources microseisms and solid Earth tides. Microseisms are generated in the oceans and on the coasts. They are usually considered as annoying noise, but for us they are signals that have a spectral peak at a period of about 6 seconds, well within the range of laboratory data, see figures 5 and $8 \mathrm{~b}$. Solid Earth tides are generated by the gravitational interaction mainly between Earth, Moon and Sun. They are easily detectable in a quiet environment, see figure 6 .

Furthermore they lend themselves to exact calculations in magnitude, direction and phase; an ideal situation to find small anomalies when comparing theoretical values with small changes in observational data. 
To familiarize ourselves with the tilt-meters and the seismometers we took advantage of three $30 \mathrm{~m}$ deep, cased boreholes at a NOAA (National Oceanic and Atmospheric Administration) site near Erie in Colorado. The boreholes had been installed 30 years ago specifically for tilt measurements. The well "seasoned" holes and the proximity to the University of Colorado made the site ideal. The tilt record clearly showed the Earth tidal tilt as the largest signal (see Fig. 6). After several months of testing and fighting and solving cable deterioration due to hungry rodents we felt it was time to install the instruments at our field site in Arizona.

The Maricopa Agricultural Center, AMC, is located about 40 mi south-east of Phoenix near the town of Maricopa. The AMC is a research and teaching site with extensive facilities for irrigation. We were fortunate that Professor Peter Wierenga and Dr. Mike Yao had built a controlled irrigation site for the study of water migration from the surface to the groundwater. The $50 \mathrm{~m} \times 50 \mathrm{~m}$ site was covered with a heavy black tarp and equipped with irrigation pipes spaced about $1 \mathrm{~m}$ apart. The field was subdivided into 6 zones that could be irrigated separately. Sampling holes allowed for water sampling from near the surface to a depth of $10 \mathrm{~m}$. The groundwater level is generally near $15 \mathrm{~m}$ or a little shallower. During irrigation, water from 2 tanks, holding about 26,000 liters each, was applied at the rate of about 3 liters/second alternating between the 6 zones. A total of approximate 45,000 liters was applied every day during a 12 hour period. The tanks were equipped with circulating pumps for mixing of additives. We irrigated twice. The first time we used water only, starting in late October of 2002 for a period of about 5 weeks. The second time we added a biosurfactant (JBR425 Rhamnolipid Biosurfactant from Jeneil Biosurfactant Co.) to achieve a concentration of $150 \mathrm{ppm}$ and irrigated for a 6 week period starting in mid October 2004 . At concentrations of $>50 \mathrm{ppm}$ the surface tension of water is reduced by more than a factor of 2 .

The soil at our site is described by D. Post et al 1988. It is characterized as Sandy Loam to Sandy Clay Loam soil.

Commencing in late August 2002 we drilled 3 holes to a depth of $10 \mathrm{~m}$ (see figure 7) and cased them with plastic pipes and quick set concrete. Within the constraints of the field site the holes were located to maximize the sensitivity for detecting changes within the irrigation site $(50 \mathrm{~m} \times 50 \mathrm{~m} \times 15 \mathrm{~m})$. The Tiltmeters (Series 5000Tiltmeters), on loan from Pinnacle Technologies in San Francisco CA, were placed in these holes and surrounded with dry sand to assure good contact. As is evident from figure $8 \mathrm{a}$ (for comparison see figure 6), it took a long time for the holes to stabilize.

The seismometers (LT-4) were installed on concrete pads at a depth of $1 \mathrm{~m}$. They were surrounded by Styrofoam and protected from water via an inverted plastic bucket. The necessary instrumentation including the data acquisition (REFTEC) was located in a nearby plastic box that was buried and covered with a tarp and approximately $10 \mathrm{~cm}$ of soil. The seismometers were on loan from Professor Craig Jones of the University of Colorado and the data acquisition systems from Passcal at New Mexico Tech in Socorro NM. Standard AC power was available at the site. The power for all instruments was provided from batteries, which had trickle chargers connected to them.

Tilt values were samples at 50 second intervals and seismic data were generated at 50 samples/second. Thus the data density for the seismic records is 2500 times greater that that for the tilt records. 


\section{$\bullet$}

\section{Data analysis.}

\section{Tilt data.}

As mentioned above (see fig 8a), it takes months for the ground to stabilize from the drilling and installation of the tilt meters. Large tilt signals are caused by nearby pumping as well as from tectonic events. Since our interest is in the tidal signal, we removed the long term trend as well as the "noise caused by pumping and tectonics. Long term trends were removed either by exponential or by low order polynomial fits to the data. Sudden changes in the signal were treated as discontinuities and the offset removed by splicing, either as DC offset or fit with a linear, possibly second order polynomial fit. We used the theoretical tide signals to chose the splice points to coincide with null values of the tides. Only after these major "noise" signals were removed did we filter the data. We employed a Butterworth filter with a bandwidth from 1 to 36 hours.

Figure 9 shows the processed tilt data for the two irrigation periods. Plotted are the correlation coefficients between the theoretical and the East-West tilts for the three tilt stations. Note the large anomaly, especially for well 2, that appears to be associated with the surfactant irrigation. The onset of the anomaly is about two weeks into the irrigation and the end about the same period after the irrigation ends. This two week period is the time for the ground to become saturated and the surface water to reach the ground water. We do not understand at this time why the anomaly for well 1 , if it exists, is so much smaller than that for well 2 . We intend to pursue this question through refined data analysis and modeling.

\section{Seismic Data.}

Figure $8 \mathrm{~b}$ shows a typical spectrum of microseisms from one of our seismometers. We chose microseisms because they are ubiquitous akin to the tides. However their intensity depends on the wave activities in the oceans, which is somewhat variable. Figure 10 clearly illustrates this variability during a one month period. Because of the large quantity of data we have only begun to reduce the seismic data. Preliminary encouraging results are shown in figure $11 \mathrm{a}$, not so encouraging ones in figure $11 \mathrm{~b}$. The figures were produced by simply taking amplitude ratios, in the microseism frequency band, between the various components without regard to the power in the microseisms. Much remains to be done in this area.

\section{Conclusion}

A three year field experiment designed to test the feasibility of detecting the infiltration of a surfactant into the groundwater was conducted. We employed tilt meters and seismometers to record spatial changes in solid Earth tides and microseisms signals caused by physical changes in an irrigated volume.

Changes in tidal signals indicate a strong anomaly associated with the irrigation when a $150 \mathrm{ppm}$ concentration of a surfactant was present. No such anomaly was detected when water only was used. Early results from the seismic data suggest that there too may be a detectable anomaly, but it is less certain. More data analysis and modeling are required before this inexpensive monitoring system should be deployed. 


\section{References and bibliography:}

$>$ Donald F. Post, Chris Mack, Philip D. Camp and Ahmed S. Suliman, Mapping and Characterization of the Soils on the University of Arizona Maricopa Agricultural Center, Hydrology and Water Resources in Arizona and the Southwest, Proceedings of the 1988 Meetings of the Arizona Section American Water resources Association and the Hydrology Section Arizona-Nevada Academy of Science, April 16, 1988 University of Arizona Tucson, Arizona.

\section{Papers published since 1996 pertaining to this work.}

$>$ Pride S., J. Harris, D. Johnson, A. Mateeva, K. Nihei, R. Nowack, J. Rector, H. Spetzler, R. $\mathrm{Wu}, \mathrm{T}$. Yamomoto, J. Berryman, M. Fehler, June 2003, Permeability dependence of seismic amplitudes, The Leading Edge pp. 518-525

$>$ Wempe, W., H.A. Spetzler, and I.C. Getting, 2003, Contaminant-induced mechanical damping at low frequencies in sandstone, SAGEEP Proceedings, pp. 973-980.

> Wempe, W., C.R. Kittleson, and H.A. Spetzler, 2003, Surface tension effects on fluid flow: preliminary lab results on the interaction of liquid contaminants and granular surfaces, SAGEEP Proceedings, 981-990.

$>$ Brunner W.M., I.C. Getting and H.A. Spetzler, A device for the independent verification of subresonant mechanical damping measurements. Review of Scientific Instruments, Vol. 74 No. 4, April 2003.

> Brunner, W. M. and H. A. Spetzler, Contaminant-Induced Mechanical Damping in Partially Saturated Berea Sandstone, Geophys. Res. Lett., Vol.29, No.16, 10.1029/2002GL015455, 2002

$>$ Schuett, H., and H. Spetzler, Capillary Crack Imbibition: A Theoretical and Experimental Study Using a Hele-Shaw Cell PAGEOPH, Vol. 158, no. 4, pp. 627-646, 2001

$>$ Brunner, W., and H. A. Spetzler, Observations of Time-dependent Meniscus Behavior with Implications for Seismic Attenuation in Three-phase Systems. GRL, Vol 28, No. 9, pp. 18671870, May, 2001

$>$ Schuett, H., J. Koehler, O. Boyd and H. Spetzler, Seismic Attenuation in Partially Saturated Dime-shaped Cracks. Pure and Applied Geophysics, 157 (2000) 435-448.

$>$ Tomusiak, S.R.A., S. Ge, H. Spetzler and M. Waite (1999) "A New Conceptual Model for Fluid Flow in Discrete Fractures: An Experimental and Numerical Study." United States Association of Computational Mechanics, Fifth U.S. National Congress on Computation Mechanics, August 1999, Boulder, Colorado, pp. 484.

$>$ Waite, M. E., S. Ge, H. Spetzler, A new Conceptual Model for Fluid Flow in Discrete Fractures: An experimental and Numerical Study, Journal of Geophysical Research, Solid Earth, Vol. 104, No. B6, 13,049-13,059, June 1999.

$>$ Waite M.E., S. Ge, H. Spetzler, D. Bahr, The Effect of Surface Geometry on Fracture Permeability: A Case Study Using a Sinusoidal Fracture, Geophys. Res. Lett., Vol. 25, No. 6, 813-816, March 1998.

$>$ Waite, W., R. Moerig, H. A. Spetzler, Seismic attenuation in a partially saturated, artificial crack due to restricted contact line motion, Geophys. Res. Lett., 24, 3309-3312, 1997

$>$ Moerig, R., W. F. Waite, H. A. Spetzler, Effects of surface contamination on fluid flow, Geophys. Res. Lett., 24, 755-758, 1997

$>$ Moerig, R., W. F. Waite, O. S. Boyd, I. C. Getting, H. A. Spetzler, Seismic attenuation in artificial glass cracks: Physical and physicochemical effects of fluids, Geophys. Res. Lett. 23, 2053-2056, 1996.

$>$ Cherry, R. H., H. A. Spetzler, and J. Paffenholz, A new wideband (1 mHz to $100 \mathrm{~Hz}$ ) seismic spectrometer, Rev. Sci. Instrum. 67 (1), pp. 215-221, Jan. 1996 


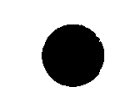

$>$ Chelidze, T. E., H. A. Spetzler, and G. A. Sobolev, Absorption of strain waves in porous media at seismic frequencies, Pageoph, vol.147, no. 1, pp. 25-55.Jan. 1996.

\section{Recent Abstracts}

Spetzler, H, R. Snieder, and J. Zhang, Monitoring Contamination of the subsurface with QuasiStatic Deformation Fall AGU Meeting, San Francisco abstract NG33B-0181, 2005

Zhang J., T. Tanimoto and H. Spetzler, Preliminary Application of Microseisms into Groundwater Contamination Monitoring Fall AGU Meeting, San Francisco abstract S12B-04, 2004

J. Zhang and Spetzler, H., Seismic and Tilt Data Processing for Monitoring Groundwater Contamination. Eos Trans. AGU, 84(46), Fall Meet. Suppl., Abstract H22C-0942, 2003

Wempe, W, Spetzler H., Kittleson, C, Pursley, J., Changes in Wetting Hysteresis During Bioremediation: Changes in Fluid Flow Behavior Monitored with Low-Frequency Seismic Attenuation. Eos Trans. AGU, 84(46), Fall Meet. Suppl., Abstract H12K-03, 2003

Zhang, J., Wempe, W., Spetzler, H. A., Field Measurements of the Seismic Absorption and Earth Strain in Partially Fluid Saturated Porous Media, Eos Trans. AGU, 83(47), Fall Meet. Suppl., 2002

Spetzler, H., Zhang J., Wempe W., Surface Energy Effects on Low Frequency Seismic Attenuation at Partial Saturation; Lab and Field. Geophysical Research Abstracts, Vol. 5, 02726, 2003, European Geophysical Society, April, 2003.

Minyard, M.L. and Wempe, W. Electrical Conductivity of Dissimilatory Metal-reducing Bacteria (DMRB) at Different Life Phases Influenced by Chromium (VI), GSA paper number 83-6-6, 2002

Kittleson, C.R. and Wempe, W., Surface Tension Effects of Common Core-cleaning Agents, GSA paper number 218-26, 2002 
Figures for Final Report for DOE-FG02-04ER15589Project Number: 1541044

\section{Seismic Absorption and Modulus Measurements in Porous Rocks in Lab and Field: Physical, Chemical, and Biological Effects of Fluids (Detecting a Biosurfactant Additive in a Field Experiment)}

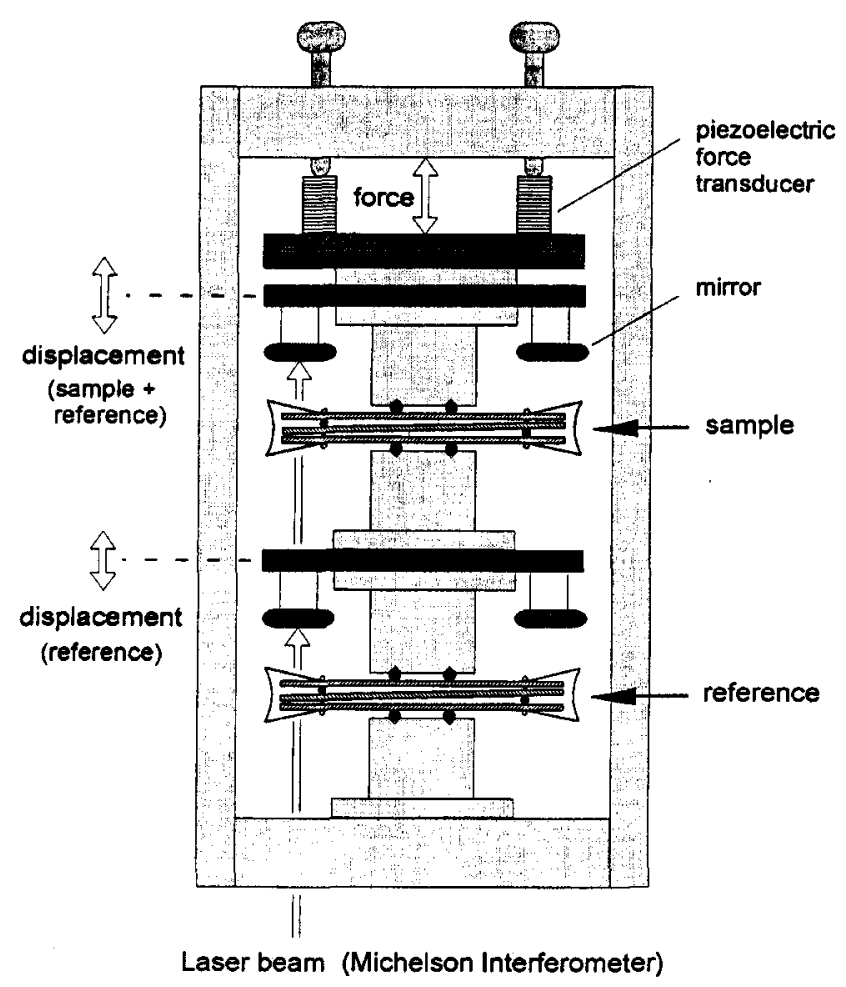

Figure 1. A schematic of the Attenuation Spectrometer is shown with two sets of double single cracks. The lower set, which contains no fluid, serves as a reference against which the top set, the sample, is measured. When rock specimens are measured, the sample becomes the rock and the reference becomes an aluminum cylinder of comparable stiffness. Three stacks of piezoelectric transducers are controlled through a function generator and serve to compress the sample and the reference. Two sets of three mirrors each are part of a Michelson interferometer and are used in the measurement of the motions of the sample and reference planes. 

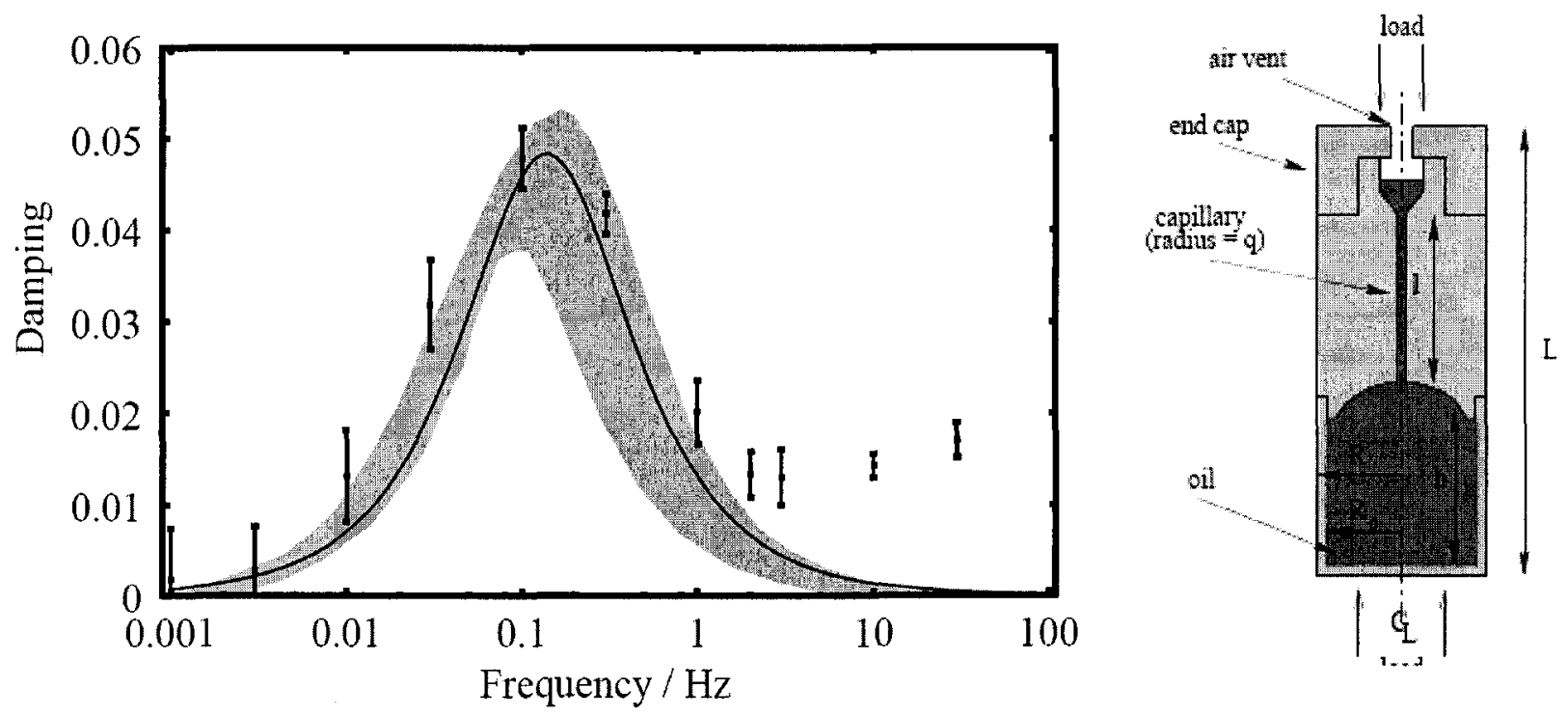

Figure 2. Data obtained with the Q-Standard are shown with error bars. The shaded area represents uncertainty in parameters used to calculate the theoretical curve (solid line). The instrument resonance occurs at $100 \mathrm{~Hz}$, thus the higher values at the higher frequencies. A sketch of the Q-Standard is also shown. 


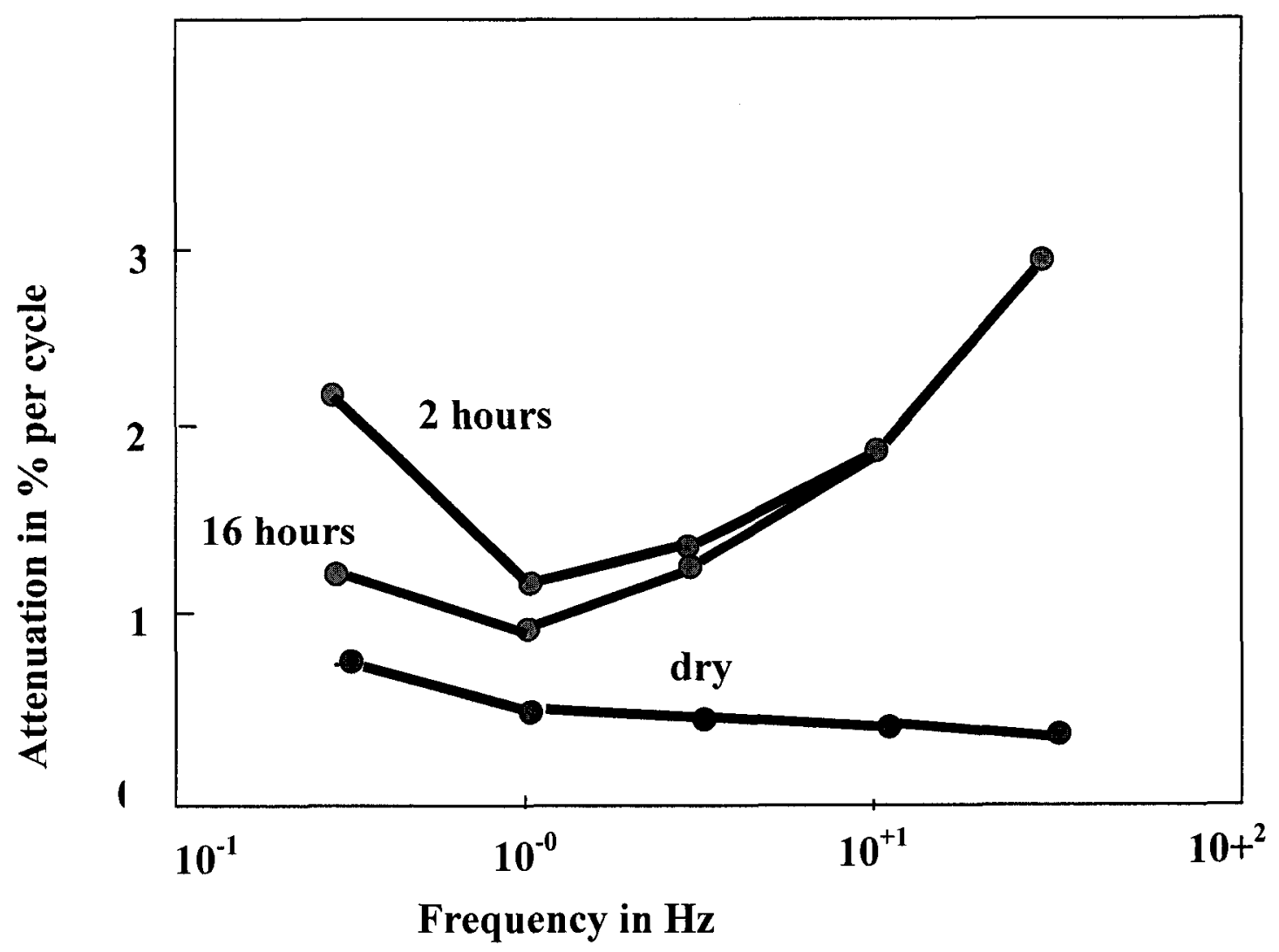

Figure 3a. The effect of the addition of water on the attenuation for a sample of Lyons Sandstone is shown. The attenuation is increased at all frequencies, but most at the high frequencies. At initial increase at the lower frequencies partially subsides again with time. The times indicate the time that passed since the water was added. 


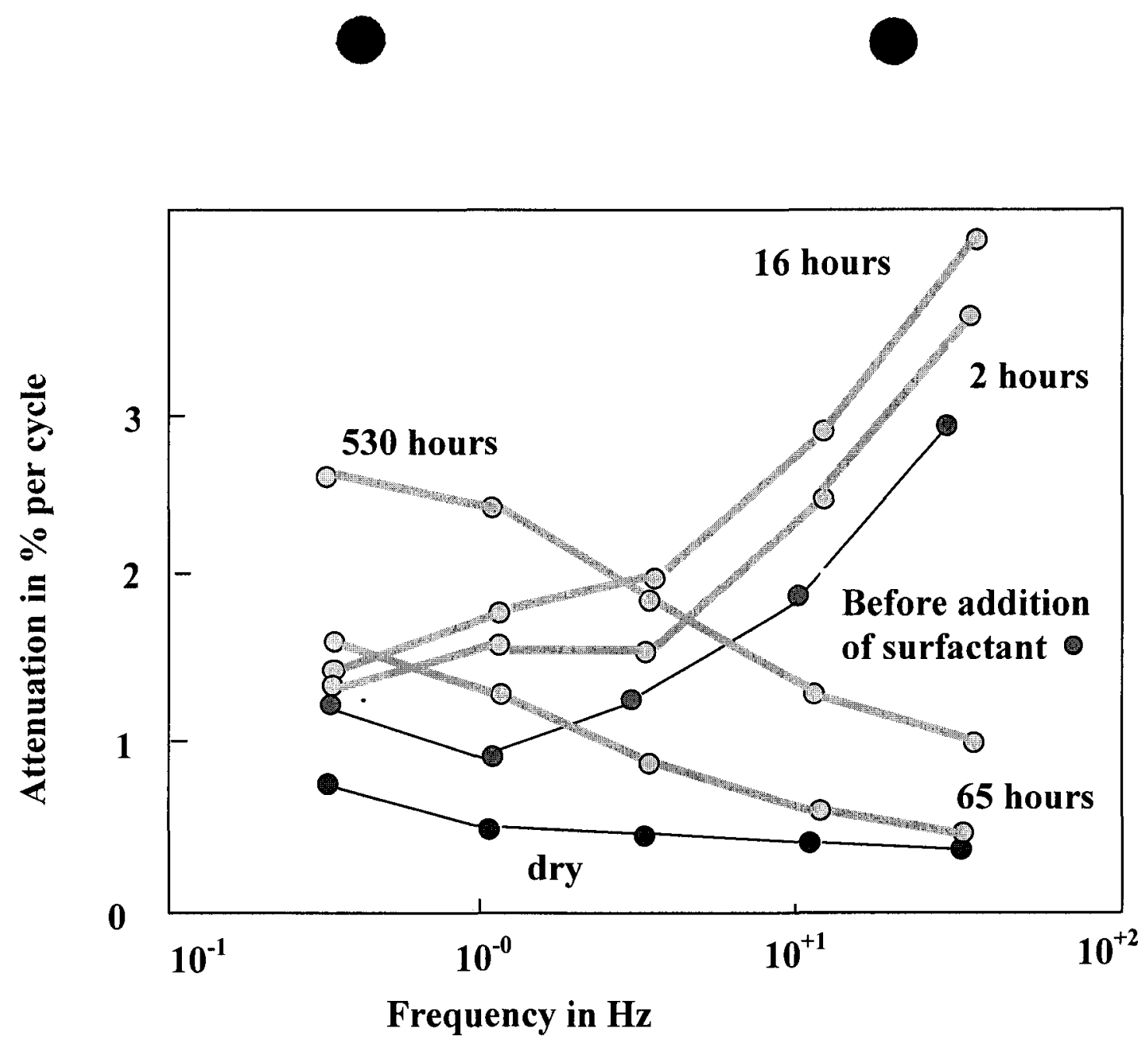

Figure $3 \mathrm{~b}$. This figure shows how the addition of a surfactant chances the attenuation for the same sample of Lyons Sandstone in Fig 3a. For reference the dry (light line and blue points) data and those taked 16 hours after the addition of water (thin line and red dots) are shown. Initially after the addition of a surfactant (sodium dodecyl sulfate) the attenuation rose at all frequencies for at least 16 hours. While it kept rising at the lowest frequencies, at the high frequencies the attenuation decreased for 65 hours and then increased again. It appears that initially the addition of water caused a high frequency attenuation peak. The addition of the surfactant caused a further increase at high frequency attenuation at first, but then a low frequency attenuation peak grew in with time and the high frequency peak nearly vanished. At least two different attenuation mechanisms are suggested. 


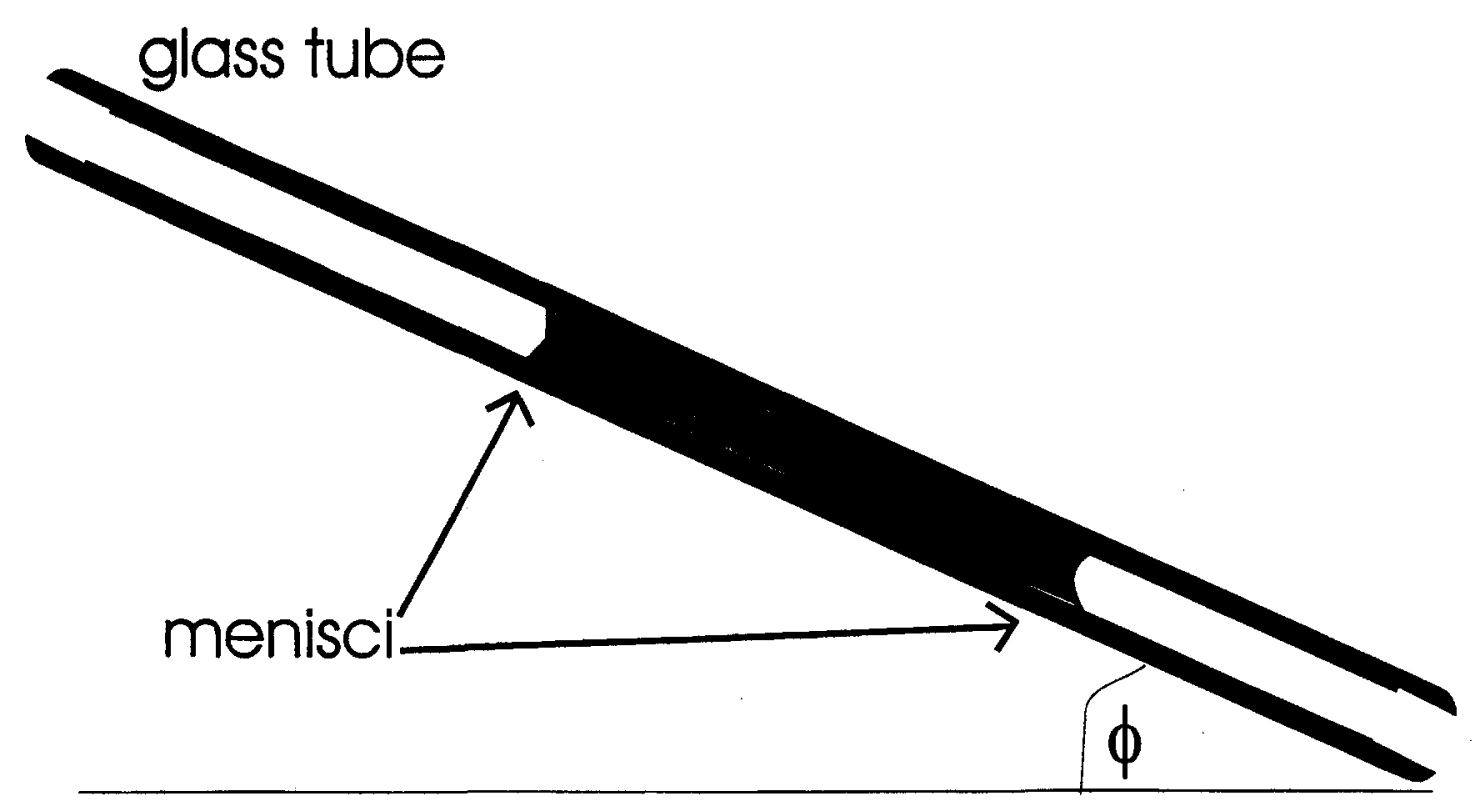

\section{Diagram of slug experiment}

Fig.4 The velocity of a slug of fluid in a capillary tube is measured as a function of the angle of inclination and contamination of the tube. Refined experiments of this type allowed us to measure the advancing and retreating meniscus forces separately. 


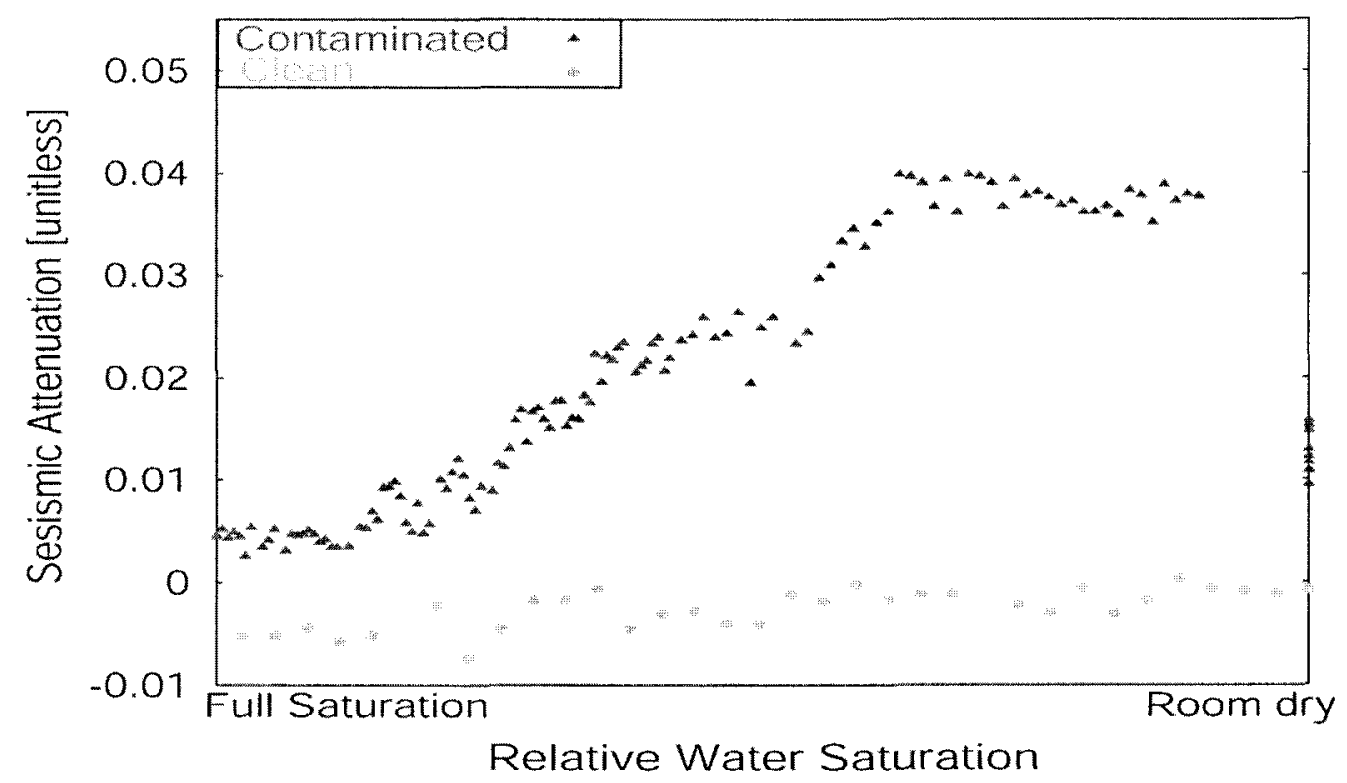

Figure 5. Effects of Contamination and Saturation on Attenuation at a frequency of 0.1 $\mathrm{Hz}$ in Sandstone: Attenuation is shown as a function of water desaturation in a clean and a propanol-contaminated Berea sandstone sample. Attenuation is apparent in the contaminated ("dirty") sample, but not in the clean sample. We interpret the high attenuation in the contaminated sample as an effect of contact angle (or wettability) hysteresis on grain surfaces in the sample while the sample is stressed. Note that the attenuation for the contaminated sample is lowest in the dry and the fully saturated state. It is in those states that there are no menisci present, thus no hysteresis. 


\section{E-W Tilt at Erie, CO site for one Week}

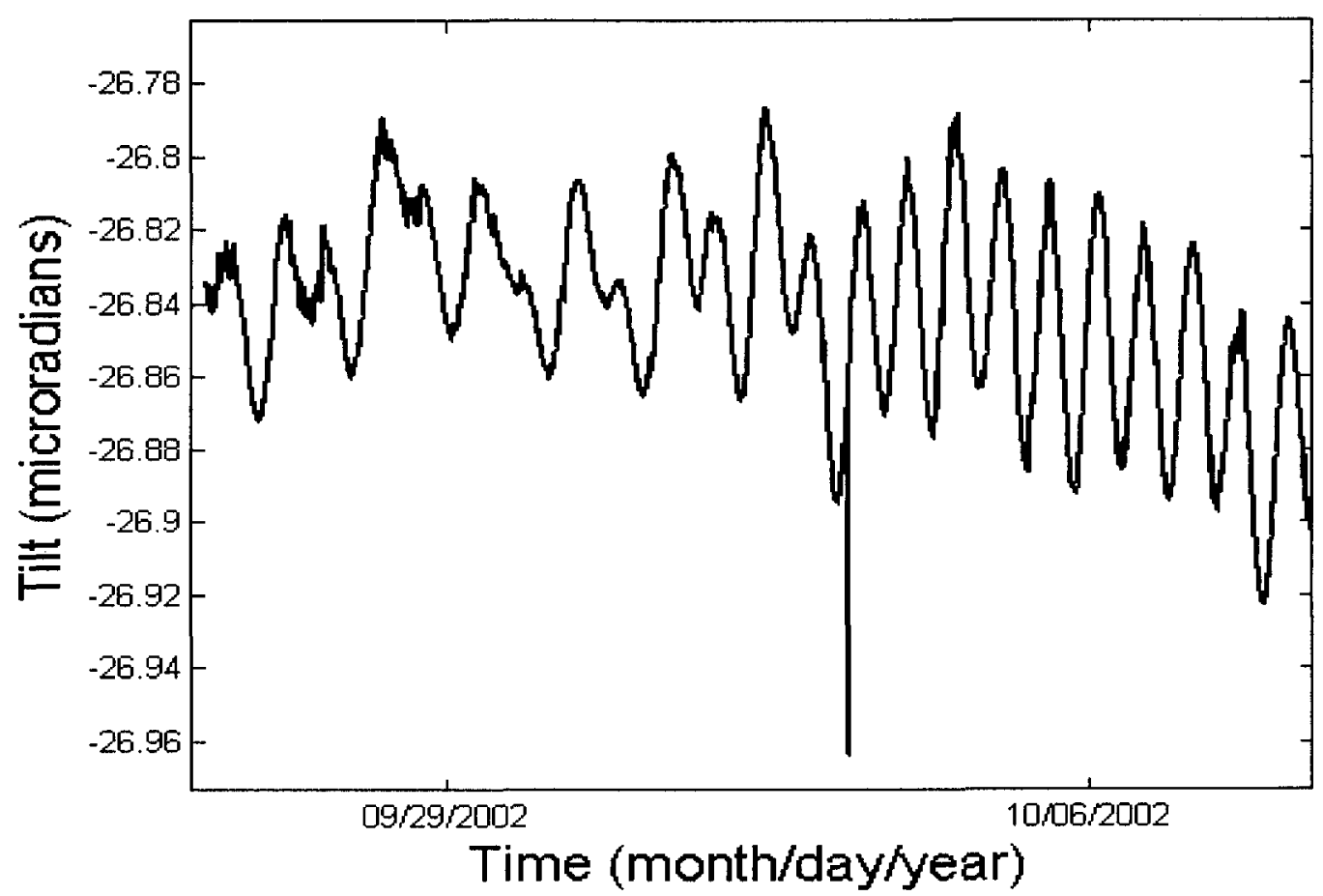

Figure 6. Unprocessed tilt data from a 30 year old hole near Erie, Colorado. The dominant signal is the solid Earth tilt. We installed our instruments in such holes to test our procedure and for our familiarization. The high signal to noise ration is an indication of the sensitivity that could be achieved for long term monitoring of sites. 


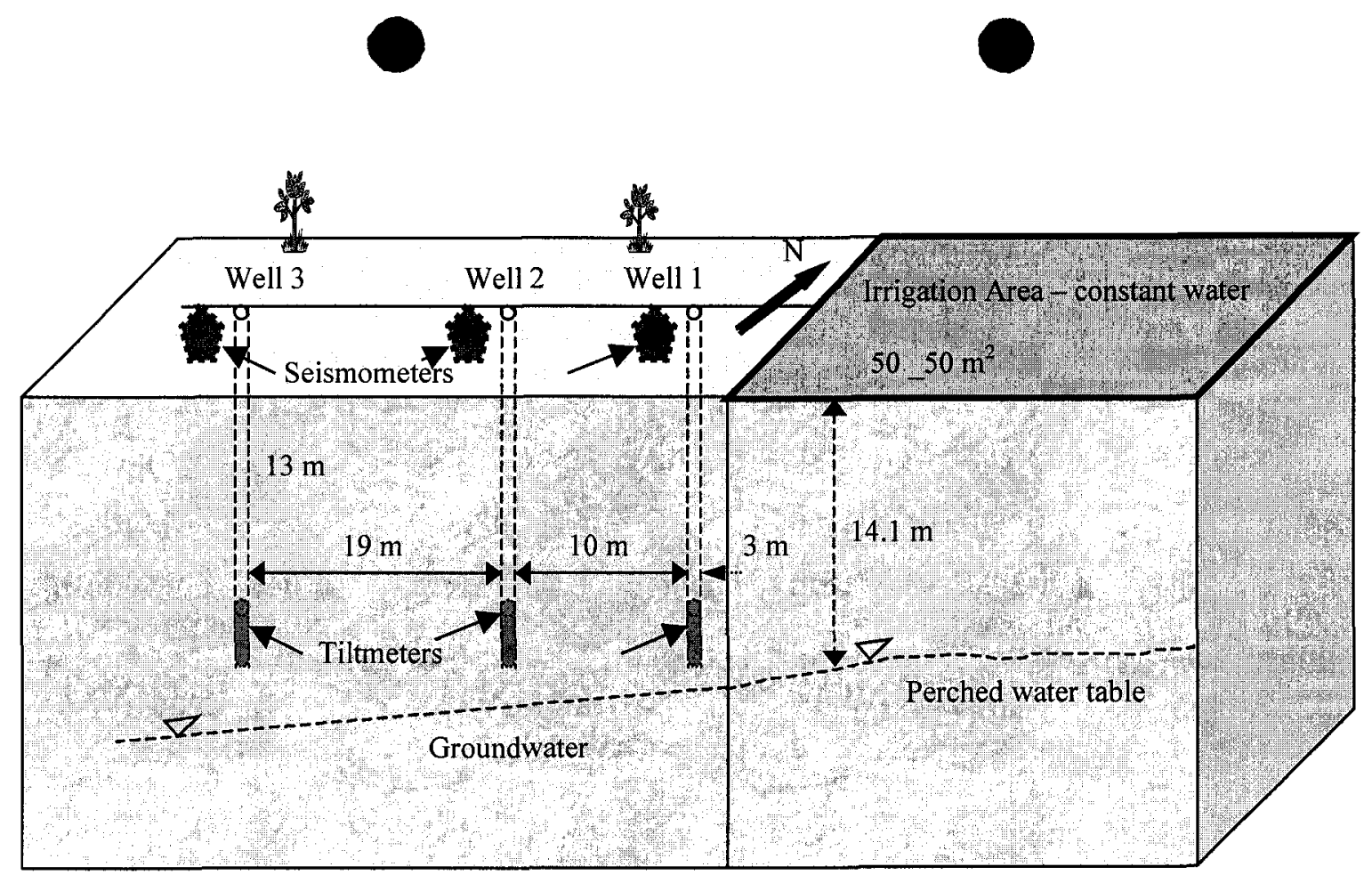

Figure 7. This schematic shows the field site in Arizona. The tiltmeters were installed at a depth of about $10 \mathrm{~m}$ in cased holes. The seismometers were buried at about $1 \mathrm{~m}$. 


\section{Tilt after Installation}

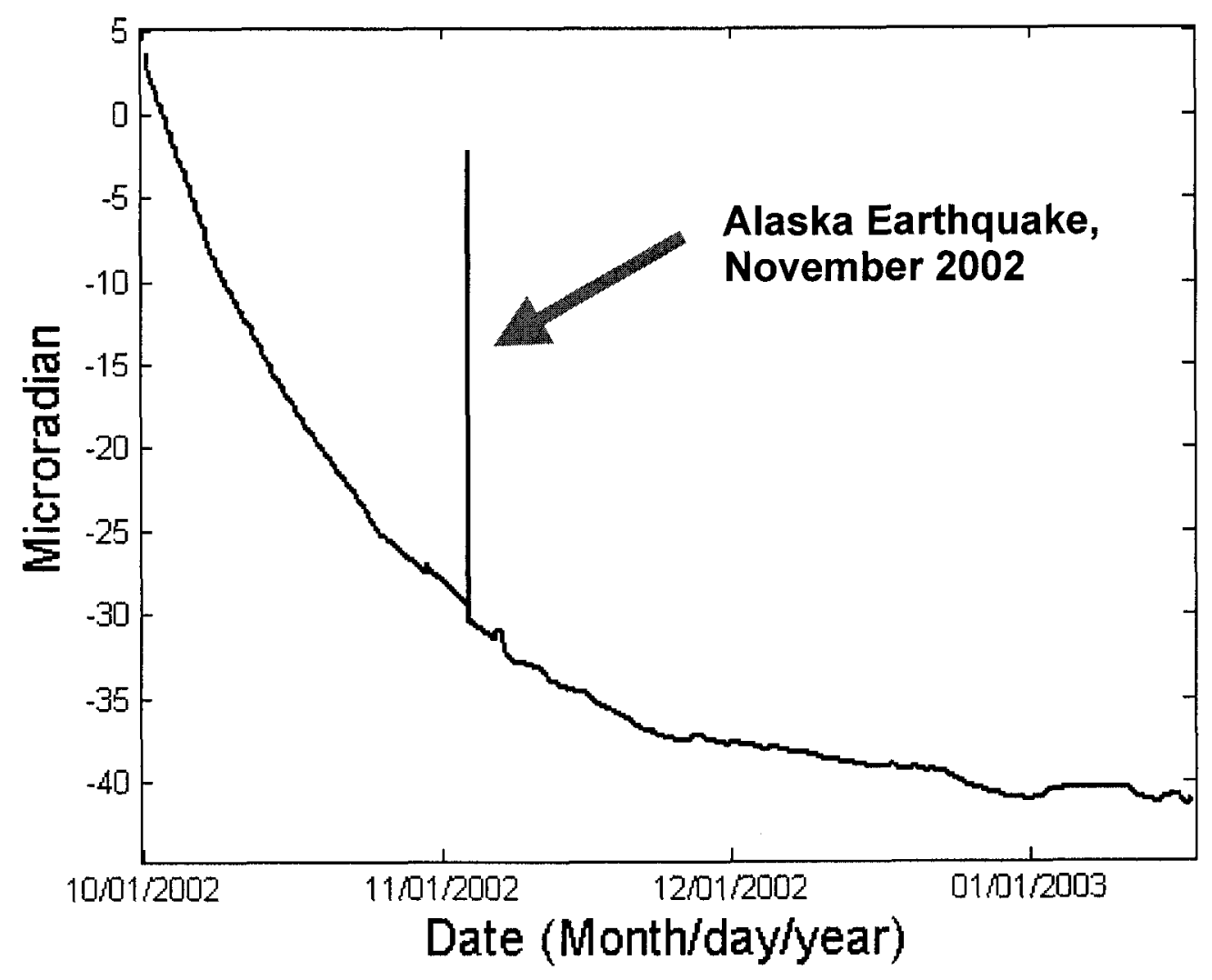

Figure 8a. Unprocessed tilt data from the Arizona site taken shortly after the instruments were installed. The tidal signals are hidden within the noise, about the width of the line. These data are to be compared with those in figure 6 . 

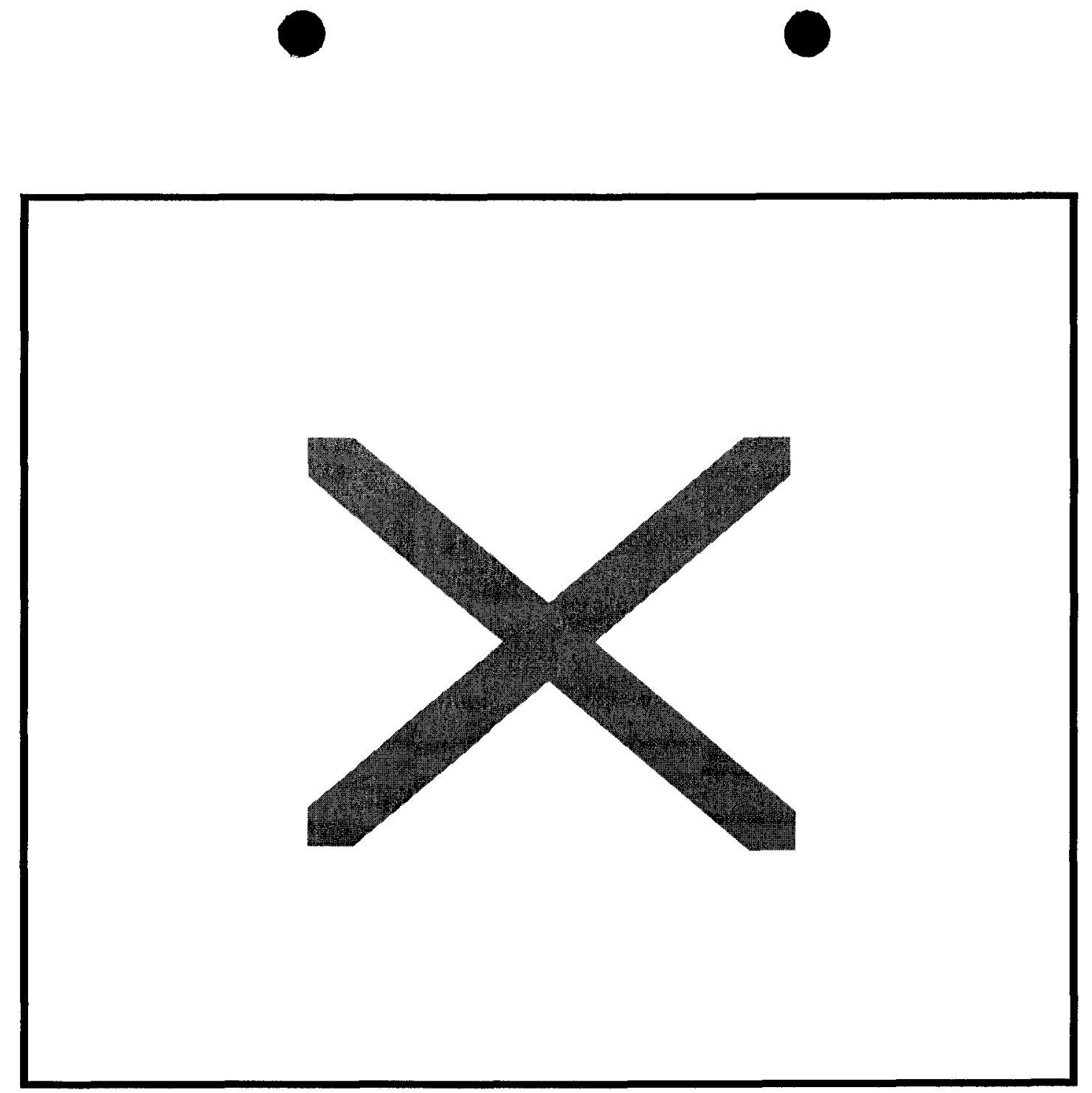

Figure 8b. A spectrum from one of our wells in the frequency range from 0.05 to $0.3 \mathrm{~Hz}$. The peak near 0.15 is due to microseisms with periods near 6 seconds. 


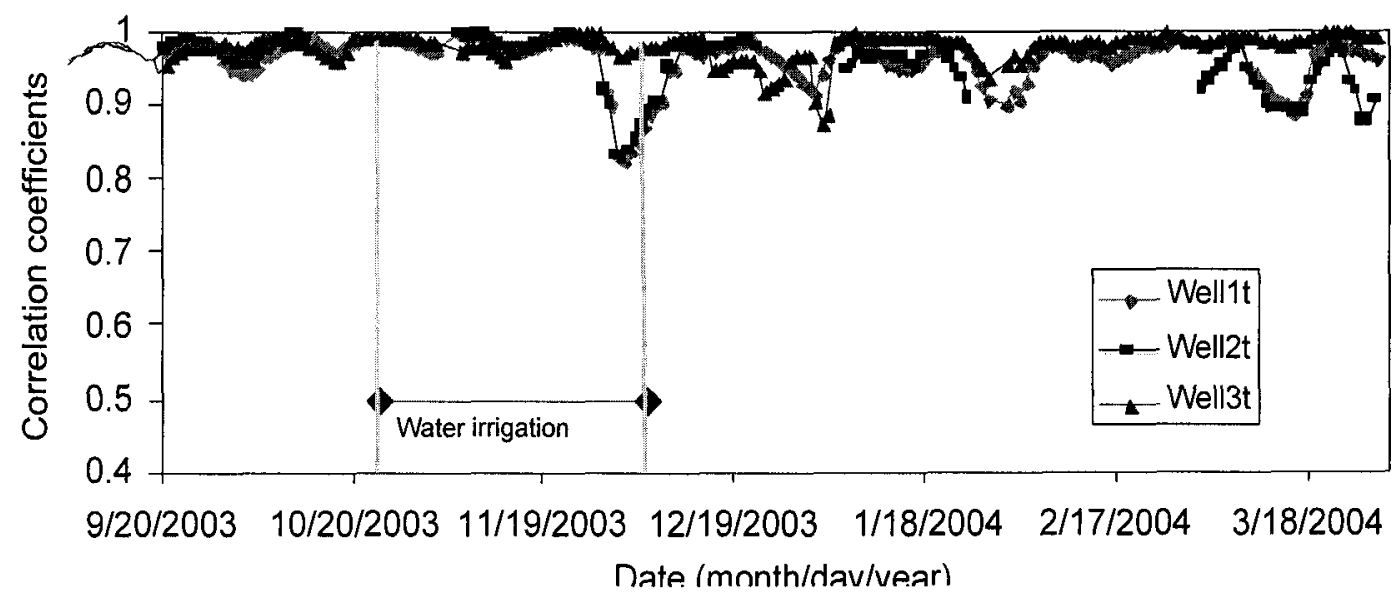

Figure 9a. The correlation coefficients between the site specific theoretical and observed tilts are plotted for all three wells. Note that the time period for irrigation with water-only is included.

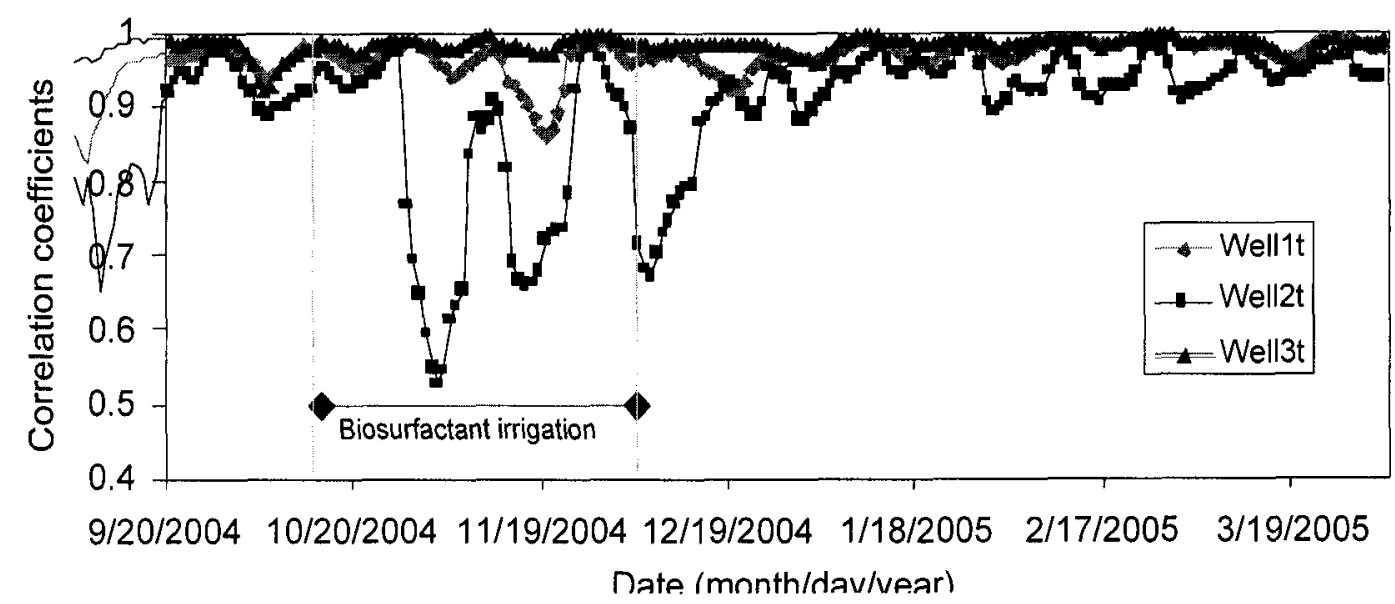

Figure $9 \mathrm{~b}$. The figure is similar to figure $9 \mathrm{a}$, but approximately one year later when the field was irrigated with a biosurfactant $(150 \mathrm{ppm})$ solution. 


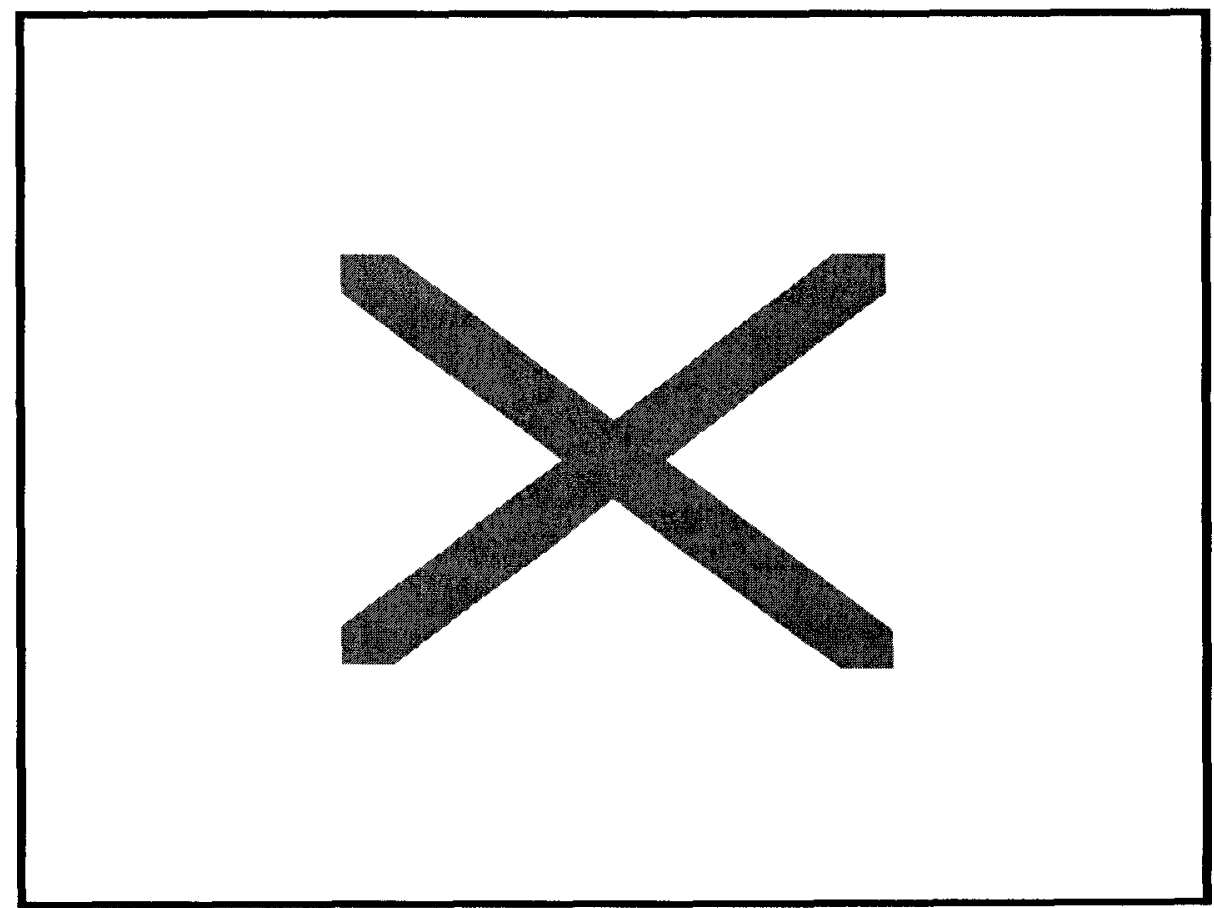

Figure 10. Power spectra are shown for a one month period for the 3 components from the seismometer of Well 2. Note how the intensity of the microseisms (frequency around $0.15 \mathrm{~Hz} 0$ varies.

Vertical Component Ratios between Wells 1 and 2

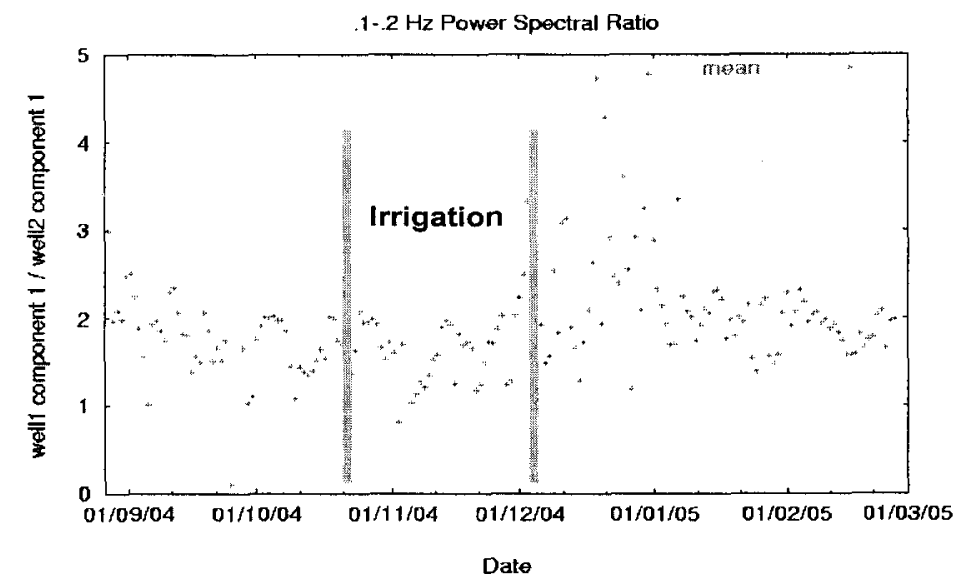

Figure 11a. Power ratios are shown for the vertical components between well 1 and 2 . Note the onset of what appears to be an anomaly several weeks into the irrigation with a surfactant. This anomaly disappears again several weeks after the irrigation ceases. For comparison look at the tilt data in figure 9. 


\section{Horizontal to Vertical Amplitude Ratio for Well 2}

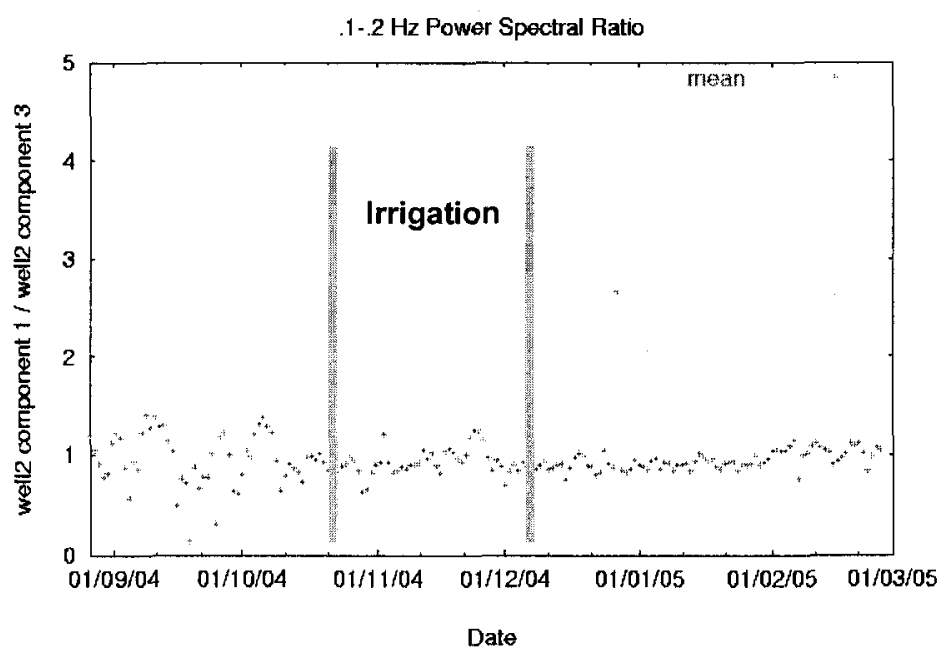

Figure $11 \mathrm{~b}$. Power ratios are shown for the vertical and horizontal ratios for well 2. No anomaly related to the irrigation is apparent. We would expect the vertical to horizontal response to change with a change in the physical properties within the irrigated volume. 